will not be influenced purely by the expected workload. A survey explicitly focused on which factors necessitate compensation seems to be needed.

Similar considerations apply to the other uses to which underprivileged area scores have been put. In the (now superseded) RAWP review the index was included in the resource allocation formula after criticism that the original formula did not take account of social deprivation. ${ }^{20}$ The research commissioned for the RAWP review did not, however, show that the use of this index would improve the fit between resource allocation and either need or demand for health services. ${ }^{21}$ There is no reason to believe that the use of other deprivation indices would do any better. ${ }^{22}$ The use of indices requires that a relation has been shown between measurements and the underlying factors which they are supposedly indexing. Stating that the underprivileged area score "is a measure of workload or pressure on the services of general practitioners" 23 is premature, and the index cannot adequately substitute for empirically validated measures in the fields in which it is being used.

GEORGE DAVEY SMITH

Lecturer in Epidemiology,

Department of Epidemiology and Population Sciences,

London School of Hygiene and Tropical Medicine,

London WCIE 7HT
1 Jarman B. Identification of underprivileged areas. BMF 1983;286:1705-8.

2 Carstairs V. Small area analysis and health service research. Community Med 1981;3:131-9. Jarman B. Underprivileged areas: validation and distribution of scores. BMF 1984;289:1587-92. . Leavey R, Wood J. Does the underprivileged area index work? BMF 1985;291:709-11.

6 Curtis SE Use of survey data and small area statistics to assess the link between individual morbidity and neighbourhood deprivation. $\mathcal{F}$ Epidemiol Community Health 1990;44:62-8.

Livingstone AE, Jewell JA, Robson J. Twenty four hour care in inner cities: two years' out of hours workload in east London obson J. Twenty four hour care in inner

8 Pitts J, Whitby M. Out of hours workload of a suburban general practice: deprivation or expectation. BMF 1990;300:1113-s.

Main JA, Main PGN. Twenty four hour care in inner cities. BMf 1989;299:627.

10 Gillam SJ, Jarman B, White P, Law R. Ethnic differences in consultation rates in urban general practice. BMF 1989;299:953-7.

11 Scott-Samuel A. Identification of underprivileged areas. BMF 1983;287:130

12 Thunhurst C. The analysis of small area statistics and planning for health. Statistician 1985;34: 93-106

13 Talbot R. Underprivileged areas and health care planning: implications of use of Jarman indicators of health care deprivation. BMF 1991;302:383-6.

14 Carr-Hill RA, Sheldon T. Designing a deprivation payment for general practitioners: the UPA wonderland. $B M \mathcal{F}$ 1991;302:393-6.

15 Jarman B. Identification of underprivileged areas. BMf 1983;287:130-1.

16 Health Departments of Great Britain. General practice in the National Health Service. The 1990 Contrace London: HMSO, 1989.

7 Department of Health and Social Security. Review of the Resource Allocation Working Party formula: final report by the NHS Management Board. London: HMSO, 1988.

18 Whitehead $M$. The health divide. In: Townsend P, Davidson N, Whitehead M, eds. Inequalities in health: the Black report and the health divide. Harmondsworth: Penguin, 1988:215-356.

19 Delamothe T. Deprived area payments. BMF 1990;300:1609-10.

20 Smith J. RAWP revisited. $B M \mathcal{J}$ 1987;295:1015.

21 Mays N. NHS Resource allocation after the 1989 white paper: a critique of the research for the RAWP review. Community Med 1989;11:173-86.

22 Carstairs V, Morris R. Deprivation, mortality and resource allocation. Community Med 1989;11 $364-72$

23 Jarman B, Bosanquet N, Rice P, Dollimore N, Leese B. Uptake of immunisation in district health authorities in England. BMF 1988;296:1775-8.

\title{
Axillary dissection in primary breast cancer
}

\section{The benefits of node clearance warrant reappraisal}

Metastases in axillary lymph nodes are the most important determinant of prognosis in patients with primary breast cancer. The management of these nodes is, however, controversial. Instead of axillary node clearance many surgeons now opt for axillary node sampling with radiotherapy to the axilla for node positive patients in an effort to reduce the morbidity associated with surgery for breast cancer. The advantages of sampling may, however, have been overestimated and those of clearance underestimated.

Morbidity in patients undergoing axillary node clearance is considerable: seromas occur in up to three fifths, all have patches of numbness or paraesthesia, shoulder mobility will be reduced, and some will develop chronic lymphoedema. Nevertheless, recent evidence suggests that surgeons can reduce the incidence of seroma considerably by paying careful attention to closing dead space. ${ }^{1}$ They can also prevent sensory loss by preserving the intercostobrachial nerve without compromising the extent of axillary dissection. Although the incidence of both seromas and sensory loss is negligible in patients who undergo axillary node sampling with radiotherapy, Aitken et al showed greater reduction in the mobility of the shoulder joint in these patients than in those undergoing node clearance. ${ }^{2}$ This influenced daily activity to a severe degree in $14 \%$ of the sampling group. Arm swelling was similar in both groups and only minor.

Although axillary lymph node sampling may allow accurate determination of metastasis in lymph nodes when expertly performed, ${ }^{3}$ in one multicentre study no lymph nodes were obtained in up to a quarter of patients in whom sampling was performed. ${ }^{+}$The opportunity to improve survival in node positive premenopausal women by using adjuvant chemotherapy will be lost if their nodal status is not determined accurately at presentation. Similarly, proper determination of nodal status is important when evaluating the benefits of adjuvant chemotherapy in node negative patients. ${ }^{5}$ In addition, serial sectioning of lymph nodes and immunohisto- chemical staining have shown that almost a third of node negative patients have micrometastases, ${ }^{67}$ the presence of which correlates positively with recurrence. ${ }^{7}$ Should further studies confirm these findings this group of patients will also require evaluation in trials of adjuvant chemotherapy for patients with node negative breast cancer.

Clinically evident recurrence in axillary nodes, preventable by axillary node clearance, ${ }^{8}$ was present in just over one fifth of patients who underwent node sampling in a study by Locker et al after a short follow up period. ${ }^{9}$ Untreated, such recurrence invades the brachial plexus and subclavian vessels, resulting in severe pain and lymphoedema, both of which are difficult to control. Nevertheless, Fisher et al showed that delay in treating the axilla in clinically node negative patients who subsequently became node positive did not adversely affect their survival. ${ }^{11}$ Moreover, the survival rates for node positive patients randomised to receive either radical mastectomy alone or mastectomy without axillary dissection but with regional irradiation were equivalent at 10 years. These studies, performed before the role of adjuvant chemotherapy for breast cancer had become established, suggest that delaying axillary clearance in otherwise adequately treated patients until they develop an axillary recurrence is unlikely to influence survival. ${ }^{10}$ This assumption has not, however, been tested in a properly controlled clinical trial.

Axillary node clearance performed through a separate axillary incision in conservative surgery for breast cancer is technically more difficult than clearance performed during mastectomy, and extra care is needed to ensure adequate clearance of all axillary lymph nodes. Removal of level II and III lymph nodes, made easier by dividing the pectoralis minor, is important for local disease control in node positive patients. A properly performed level I axillary node dissection, however, is adequate for staging. ${ }^{.1}$ Specimens taken at node clearance should yield an average of 20 or more lymph nodes for each specimen. Specimens taken at sampling should 
probably have four or more lymph nodes for adequate staging.

Almost half of all patients with a palpable primary breast cancer will have lymph node metastases at presentation compared with only one fifth of those with a non-palpable cancer detected on mammography. Preliminary work on immunoscintigraphy promises some hope in determining nodal status preoperatively and warrants further research. ${ }^{12}$ Subcutaneous administration of radiolabelled monoclonal antibody seems to be preferable to intravenous administration. False negative and false positive results remain a problem, but the rates should be diminished by the use of more specific monoclonal antibodies, antibody fragments, better radioisotopes, and more sensitive imaging techniques. Ultrasonography has also been investigated for determining lymph node status preoperatively; although much more sensitive than clinical examination, its specificity is low, yielding no overall improvement in prognostic information. ${ }^{1}$

Hormone receptors, tumour markers, oncogenes, growth factors, and measurements of proliferative rate have all been suggested as alternative means of identifying patients with a poor prognosis. All are still in the investigational phase, however, and, except for oestrogen receptors, have not proved to be independent prognostic indicators. Preliminary results on the HER-2/neu gene, a member of the erb $B$ oncogene family, are encouraging. ${ }^{1+}$ Amplication of HER-2/ neu seems to correlate with the number of positive lymph nodes and is also an independent predictor of overall survival and time to relapse in node positive patients.

Accurate preoperative determination of lymph node status in primary breast cancer would have many advantages. Both sampling and clearance could be avoided in node negative patients and clearance reserved for node positive patients; radiotherapy to the axilla could be avoided in all patients with operable primary breast cancer; and treatment options could be discussed in detail before surgery. Until this is possible, however, the evidence suggests that axillary node clearance provides the most reliable method of determining lymph node status, an excellent method of local disease control, and a reduced incidence of long term complications when compared with axillary node sampling and radiotherapy in patients with primary breast cancer.

Senior Lecturer in Surgery,

P J O'DWYER

Western Infirmary,

Glasgow G11 6NT

1 O'Dwyer PJ, O'Higgins NJ, James AG. Effect of closing dead space on seroma incidence following mastectomy. Surg Gynecol Obstet (in press).

2 Aitken RJ, Gaze MN, Rodger A, Chetty U, Forrest APM. Arm morbidity within a trial of mastectomy and either nodal sample with selective radiotherapy or axillary clearance. $\mathrm{Br} \mathcal{F}$ Surg 1989;76:568-71.

3 Steele RJG, Forrest APM, Gibson T, Stewart HJ, Chetty U. The efficacy of lower axillary sampling in obtaining lymph node status in breast cancer: a controlled randomised trial. $\mathrm{Br} \mathcal{F}$ Surg 1985;72:368-9.

4 Forrest APM, Stewart HJ, Roberts MM, Steele RJC. Simple mastectomy and axillary node sampling (pectoral node biopsy) in the management of primary breast cancer. Ann Sur 1982;196:371-8.

5 Donegan WL. Are we positive about node negative breast cancer? f Surg Oncol 1990;43:199-202. 6 Saphir O, Amromin G. Obscure axillary node metastasis in carcinoma of the breast. Cancer 1948;1:238-41.

Trojani M, De Mascarel I, Bonichon F, Coindri JM, Delsol G. Micrometastases to axillary lymph nodes from carcinoma of breast: detection by immunohistochemistry and prognostic significance. Br f Cancer 1987;55:303-6.

8 Veronesi U. Treatment of primary breast cancer. Baillieres Clinical Oncology 1988;2:175-92.

9 Locker AP, Ellis IO, Morgan DAL, Elston CW, Mitchell A, Blamey RW. Factors influencing loca recurrence after excision and radiotherapy for primary breast cancer. Br F Surg 1989;76:890-4.

10 Fisher B, Redmond C, Fisher ER, et al. Ten-year results of a randomised clinical trial comparin radical mastectomy and total mastectomy with or without radiation. $N$ Engl f Med 1985;312:674 81 .

11 Fisher B, Wolmark N, Bauer M, et al. The accuracy of clinical nodal staging and of limited axillary dissection as a determinant of histologic nodal status in carcinoma of the breast. Surg Gynecol Obstet 1981;152:765-72.

12 Athanassiou A, Pectasides D, Taylor-Papadimitrious J, Epenetos A. Immunoscintigraphy with 1311-labelled HMFG2 and F(abl)2 HMFG1 in the pre-operative detection of clinical and 1311-labelled HMFG2 and $F(a b 1) 2$ HMFG1 in the pre-operative

13 Tate JJT, Lewis V, Archer T, Guyer PG, Royle GT, Taylor I. Ultrasound detection of axillar lymph node metastases in breast cancer. Eur F Surg Oncol 1989;15:139-41.

4 Slamon DJ, Clark GM, Wong SG, Levin WJ, Ullrich A, McGuire WL. Human breast cancer: correlation of relapse and survival with amplication of the HER-2 neu oncogene. Science 1987;235:177-82.

\section{Delaying community care}

\section{3 is too far away: why not April 1992?}

No sooner had the new community care legislation become statute last summer than the government delayed its implementation until April 1993-to the "never never" land beyond the next election. The preceding six months of hectic but enthusiastic joint planning between health and social services authorities slowed down to its usual desultory pace as frustrated fury at the news gave way to despondency. Although the Social Services Inspectorate produced a sensible programme of phased targets designed to encourage local authorities to use the available time productively, inspectors acknowledged that it was almost impossible to maintain momentum and enthusiasm.

The reason for the delay was the government's realisation of the costs that local authorities would incur by taking on their new responsibilities. Local authority associations estimated that in 1991-2, $£ 829 \mathrm{~m}$ would be required. The government has not made known its own estimates-if it has any-but it has made clear that the pace of introducing changes will be determined by the consequences on the level of community charge. The Association of Metropolitan Authorities calculated that an extra burden of $£ 15$ would fall on each community charge payer each year. ${ }^{1}$

Furthermore, the government had no confidence in local authorities' ability to implement the proposals efficiently. According to the then Secretary of State for Health, $\mathrm{Mr}$ Kenneth Clarke, "It has become overwhelmingly clear that many local authorities are not managing their services and their spending so that they deliver good quality services effectively within reasonable spending limits."2

The charges of profligacy and irresponsibility laid at the feet of local government look like a clear case of the pot calling the kettle black, when the likely impact of the delay on central government spending on social security benefits is considered. Clearly setting out the effects of the delay is an excellent new briefing paper from the King's Fund Institute, All things come (to those who wait?). ${ }^{3}$ Readers will remember that an important reason for the new proposals was the need to cap escalating social security spending on residential and nursing home care. It had increased from $£ 10 \mathrm{~m}$ to $£ 878 \mathrm{~m}$ between December 1979 and May 1988, and the most recent official estimates suggest a figure of $£ 1200 \mathrm{~m}$ to $£ 1300 \mathrm{~m}$ for the year ending March 1991. If the growth rate continues at $30 \%$ a year, as it has done recently, the total could reach $£ 1.9$ billion by $1992 .{ }^{+}$ This could rise further over the next two years because health authorities are now scrambling to transfer as many long stay care clients as possible out of NHS funded places into places managed by charitable trusts working within the independent sector, housing associations, and complicated consortiums specifically designed to take advantage of the current funding arrangements before the drawbridge is pulled up in April 1993. Delaying the changes in community care may cost central government $£ 520 \mathrm{~m}$. 